\title{
Effects of Public Policies and Labor Market on the Fertility of Japanese Women: Analyses of Municipal Data*
}

\author{
Seiritsu OGURA \\ Hosei Institute on Aging, and Faculty of Economics, Hosei University \\ sogura@hosei.ac.jp \\ Tamotsu KADODA \\ Faculty of Economics, Daito Bunka University \\ tkadoda@ic.daito.ac.jp
}

\begin{abstract}
In this paper, we examine the differential effects of young male and young female labor markets on fertility by municipal data. We constructed a panel of more than two thousand municipalities from the Census data of 1985 to 2005 , and supplemented them by administrative reports. As our dependent variable, we constructed a weighted fertility rate index using the Census Data that is a good proxy for TFR for municipalities, but free from the influence of observations of other periods. We then applied the standard specification that had been widely used to account for the changes in TFR, using regional data. Our fixed effect estimation result shows that even though the weakening preference for children still accounts a substantial portion of the fertility decline experienced during 2000-2005, labor market factors have become more important, including the increased female labor force participation, and the increased uncertainty in the employment for younger male workers. Compared with the existing studies, the increased data size, the reduction in community heterogeneities, and the better quality of Census Data of our study seem to have produced more precise estimation results.
\end{abstract}

\footnotetext{
* Earlier versions of this paper had been presented at a workshop in Hitotsubashi University in 2008, and at CIS-IFO Workshop in Munich in February 2008. The authors would like to thank for the valuable comments by Professor Sachiko Kuroda of Hitotsubashi University and other participants of the workshops, and two anonymous referees of this book. We are very grateful to the financial support from the academic project on Economic Analysis of Intergenerational Issues, funded by the Grant-in-Aid for Specially Promoted Research from Japan's Ministry of Education (grant number 18002001) and from Hosei University.
} 


\title{
Effects of Public Policies and Labor Market on the Fertility of Japanese Women ${ }^{\dagger}$ : Analyses of Municipal Data
}

\author{
Seiritsu OGURA, Hosei Univ. \& Tamotsu KADODA, Daito Bunka Univ.
}

\section{Introduction}

During the last thirty five years, Japan has experienced a rapid decline in the number of children born, from 2.09 millions in year 1973 to 1.06 millions in year 2005. During this period, the total fertility rate of Japanese women dropped from 2.16 in 1971 to 1.26 in 2005 (see Figure 1b in Warren Sanderson's paper). As a result of this rapid decline in the fertility, many Japanese public institutions came under serious attack on their sustainability questions. Most notable of such examples were public pension programs and public health insurance programs that had been transferring huge amount of resources from the working generation to the retired generations. They have been the core of Japanese welfare state, and the most important keys to the continuous political success of the Liberal Democrats during the last half a century. These programs were, and they still are, primarily financed by payroll taxes, and Japanese voters had showed strong dislike of taxing capital income or consumption. With the rapid growth of elderly population, Japan had become extremely vulnerable to such a shock.

The fertility shock was first felt in 1990 when the government reported a very sharp decline in TFR. It was actually 1.57 , contradicting the optimistic population projection of the government that had placed the long term TFR at the replacement level of 2.0. The news of the fertility shock could not have come at a worse time for the government, as the news coincided with the spectacular collapse of the "bubble economy". In fact, the bubble economy could have contributed significantly to the initial decline in fertility by inducing behavioral changes in younger women, as the unprecedented economic boom had opened career opportunities for women graduating from colleges in major corporations for the first time. Furthermore, the boom encouraged the consumption of expensive brand-name clothes, jewelries, foreign travels, etc., at a cost affordable only to working, but single, women.

The stock market collapsed spectacularly in 1989, and in the severe economic crisis that followed, most large corporations abandoned their traditional personnel management model, particularly the practice of lifetime employment. They began firing middle-age workers before the mandatory retirement age, and, instead of hiring thousands of college graduates a year, they stopped hiring them altogether. For almost a decade and a half after the collapse, the labor market for graduating college students had been in an "ice age". Even when the business eventually turned better, and firms needed more workers, they did not resume hiring regular employees for a while. Instead, they either hired part-time workers, or turned to personnel services for dispatched workers.

As a result of these changes in the corporate hiring practice, now one out of three Japanese workers is a

$\dagger$ Earlier versions of this paper had been presented at a workshop in Hitotsubashi University in 2008, and at CIS-IFO Workshop in Munich in February 2008. The authors would like to thank for the valuable comments by Professor Sachiko Kuroda of Hitotsubashi University and other participants of the workshops, and two anonymous referees of this book. We are very grateful to the financial support from the academic project on Economic Analysis of Intergenerational Issues, funded by the Grant-in-Aid for Specially Promoted Research from Japan's Ministry of Education (grant number 18002001) and from Hosei University. 
part-time worker. Looking back to 1994, there were 38.1 million regular workers, and 9.7 million part-time workers. In 2007, however, there are 33.9 million regular workers, and 17.2 million part-time workers. Two-thirds of the part-time workers are female, but even for men, in 1994, there were 26.4 million regular workers and 2.4 million part-time workers, but, in 2007, there are only 23.9 million regular workers and 5.4 million part-time workers. Most of these part-time workers are left outside of the protection of such social insurance programs as public pension for employees, public health insurance for employees or even unemployment insurance.

The government, faced with the disintegrating corporate employment, adopted a series of policies to protect the jobs of older workers. In 1994, the lower-limit of the mandatory retirement age was moved up to age 60 from age 55, and generous subsidies have been offered to the firms for keeping the older workers employed after age 60. The government did little in improving the fortune of young workers in the "ice-age" labor market. At the same time, as we will see in the next section, the government was trying to respond to the challenges of declining fertility by offering female workers child-care leaves, improved public nursery school services, and slightly more generous child benefits. In spite of these measures, the total fertility rate kept on falling, and forced the government to revise its population projections twice downwards. In short, these policies have been quite ineffective.

What has been missing from these policies? The key lies in the experience in 2006, when TFR went up slightly for the first time in almost two decades. The demographers of the Ministry of Health and Welfare credited the upturn to the increased hiring of younger male workers as regular employees in the preceding years, who got married and had children. In this paper, we want to examine the role of employment security in determining the fertility and the labor markets. In the remainder of this paper, we are going to find out how much of the decline in fertility since 1995 is due to the labor market conditions, particularly young men and women in the prime of reproductive ages. Our analysis suggests that in the decline in fertility during the last five years, the job uncertainty of young male workers had been very important.

The rest of this paper is constructed as follows; first, in 2, we will outline the policy measures against the fertility decline, and in 3, we will give a survey of the empirical studies on the effectiveness of these measures. In 4, we will explain how we are going to construct our own fertility variable for our regression analyses, and in 5, we will explain our specification and the independent variables. In 6 , we will discuss the results of our estimation, and in 7, we will summarize our findings and discuss their implication on Japanese public policies.

\section{Public Policies after the Fertility Shock}

Following the fertility shock, in August 1990, an inter-ministerial liaison conference on child-raising support policies was created. From there, in 1992, two policies were put into effect.

First was the expansion in child-care benefits; starting 1992, a first child would receive a benefit of 5,000 yen per month during its first year, a second child receive the same benefit for its first five years, and a third child on would receive 10,000 yen per month during the same period. During the 1988-1991 period, a first child would receive no benefit, a second child would receive 2,500 yen, and a third child 5,000 yen until they start going to elementary schools. In Table 1, we have shown the changes in the eligibility of the child-care benefits in terms of the order of birth and the age of the child, and the amounts of benefits. For 
the sake of simplicity, in the table, we have expressed a condition like "until the child starts going to primary school" as "less than 7 years old", etc..

Secondly, by a 1991 legislation, child-care leave became formally a legal right of workers if they were caring for a child less than one year old. We should note, however, that a 1975 law had provided a child-care leave to the female workers in compulsory education institutions and nurses and care-givers in medical and social welfare institutions. Under the old law, a female teacher was given one year leave, during which a substitute teacher was appointed and a benefit equal to social insurance fees would be provided. This new law neither obligated the employers to hire a temporary staff for a woman taking the leave, nor provided benefits during the leave. For this reason, two additional laws, one for national government employees and the other for local government employees, were quietly passed in 1992 .

In December 1994, ministers of education, health and welfare, labor and construction agreed on the fundamentals of Child-Raising Support policies, and jointly announced the "Angel Plan". Following the plan, several measures were put into effect, including the extended hours of public nursery care, provision of child-care leave benefit, legislation of 40 hour week, etc.. The most important component of the plan was the improved nursery school services for working mothers; the government pushed the municipalities to offer longer care hours in their nursery schools, and at the same time, it decided to increase the capacities of public nursery schools steadily over the five year period (1995 to 1999).

The second was the new benefits introduced into the unemployment insurance in 1996 to cover the social insurance fees (public pension, health, employment etc.) during the child-care leave. The basic benefit was set equal to 20 percent of the wage (subject to an upper-limit) during the leave and an additional benefit equal to 10 percent of the wage will be paid when they return to the same employer. According to a government survey, the proportion of eligible women actually taking the leave was already 49.1 percent in F.Y. 1996, and in F.Y. 2004, the proportion climbed up to 70.6 percent (Equal Employment Survey).

In January 1997, the government announced its new population projection, in which the government abandoned its "temporary adjustment" theory and revised their long-run TFR projection downward (from 1.80 to 1.61) for good. In December 1999, "New Angel Plan" was created as an agreement between the five ministers and the minister of home affairs. Under the new five year plan (2000-2004), the government promised to continue to offer more nursery schools, more facilities with extended hours and with infant cares.

In 2002, the government announced its population projection, in which the long-run TFR assumption was reduced further down to 1.39. According to the Ministry of Health and Welfare, a part of this downward adjustment was attributable to the decline in marital fertility. For this reason, much more comprehensive measures, than just helping working mothers in raising children, were needed. They were (a) adjustments in the working habits of men and women, (b) community supports, (c) support for next generation by social security systems, and (d) promotion of socialization and independence of children. In March 2003, the inter-ministerial conference had approved these principles in the Immediate Guidelines Concerning the Support for Next Generation, and in July of the year, Law to Support Raising Next Generation was born.

A new component in this plan was an attempt to reform the work-life balance of all the workers, including male workers. The new Support Law mandated firms with more than 301 employees to make up 
its own action-plan to make itself a family-friendly one and register them with the Labor Standards Inspection Office. In an action-plan, a firm is asked to pledge to provide employees child-care leaves and reduce their workloads when they ask, and when more than $70 \%$ of its new mothers (and one new father) have taken the child-care leave, it is approved officially as a family-friendly firm. In December 2008, the law has been strengthened in two ways; the firms with more than 301 employees are now required to inform the employees of their action-plans, and starting in 2011, the law will be applied to firms with more than 101 employees.

3. Survey of Japanese Literature on Fertility Decline and Various Policy Measures

Causes of Fertility Decline

Among the Japanese economists, Ogura and Dekle (1992) was the first to analyze the causes of declining Japanese fertility by econometric analyses. For their analysis, they computed their own prefectural fertility index directly from the Census data and Vital Statistics data for four Census years (1970, 1975, 1980, and 1985). Using the difference in difference method, they have estimated the marriage functions and fertility functions for three major age-classes (20-24, 25-29 and 30-34) separately. Their independent variables (prior to differencing) include proportion of married female in the last census, female wage rate, male-female wage ratio, unit land price, unit rent, proportions of higher education for men and women, and the ration of single male and single female. They have shown that (1) fertility rates depend most critically on the sizes of women population married in the last five years. Their estimation shows that (2) the most important factor in accounting for the lower marriage rates of women in their 20's is their higher education, (3) a higher female wage rate decreases the marriage rates women except for the 20-24 class, and (4) it also decreases their marital fertilities as well, and (5) while a higher housing cost does not seem to reduce marriages, it reduces the fertilities (except for 20-24). Since none of these factors involved, namely, higher female wage rates, more women with higher education and higher housing costs, could be considered temporary phenomena, Ogura and Dekle concluded that decline in fertility would not reverse itself as the government had been hoping for.

Takayama et al (2000) is an example of the empirical works that have used the prefectural TFR data as the dependent variable. Their right hand side variables include male and female wages, price index for education, kindergarten and nursery school capacity ratios, unit housing cost, child benefits, child welfare expenditure, marriage rate, first marriage ages, divorce rate, various transfer incomes etc.. They have used ten years (1985 to 1994) of prefectural data for their pooled cross-section OLS. They reported having significant right signs for male wages $(+)$, female wages $(-)$, unit housing cost $(-)$, nursery school (+), but wrong signs for education cost, kindergarten, child benefits, and child welfare expenditure, etc. without prefecture dummies. They also report that most of these variables except income variables lost their statistical significance when they included year and prefecture dummies.

\section{Effects of Child benefit}

There seems to be a loose consensus among the empirical economists that child benefit has a positive but relatively small effect on fertility. Using 1985 prefecture TFR data, Harada and Takata(1993) has estimated the fertility equation and applied the results to assess the effect of the change in child benefit system. They have chosen household income, female wage income, land price, higher education ratio, and 
education expenditure per student as independent variables. According to their simple cross-section OLS estimation, the elasticity of TFR is around -0.25 to -0.35 with respect to female wage rate and -0.15 to -0.30 with respect to housing costs. From these results, they have done a simple policy simulation on the effect of the change in child benefit that had made the first child eligible for a grant of 5,000 yen. They argued that the average wage income of women was 195,728 yen per month, and a grant of 5,000 yen was equal to 2.5\%; hence, the grant should reduce the cost of caring a child by $2.5 \%$. Given the coefficient of female wage income, or -0.25 , the effect should be less than $0.6 \%$. They have concluded that the measure is costly and not very effective.

More recently, Abe and Harada (2008) estimated a birth rate function using municipal TFR data of year 2000 as the dependent variable, and average income, female wage income per month, unit land price, an index of education, and an index of nursery capacity constraint, for independent variables. Some of their independent variables, for example, female wage income, are prefectural level variables as no municipal level data are available. They have obtained the following elasticity estimates; namely, - 0.14 for income, -0.27 for female wage, -0.06 for land, and -0.18 for nursery capacity constraint. From these results, they estimate that 10,000 yen child benefit will, on the one hand, reduce the cost of child-service by $4.5 \%$, which will increase the demand for children by $1.2 \%$ (or $0.27 \times 4.5 \%$ ). But on the other hand, it will increase in household income, and will decrease the demand for children by $0.3 \%$ (or0.147x2.5\%).

We have to point out that, technically, both of these two papers by Harada and his associates are based on simple OLS estimation applied to single year cross-section data, and they are subject to spurious correlation problems.

A similar negative conclusion has been reached by Morita (2005), who has used an IPSS survey (Female Labor and Child Raising 2004) of modest sized samples (778 households). She estimated the excess demand function for children, defined as the ratio of ideal number of children to the actual number of children, with the (per child) care-cost function as an endogenous variable. Unlike Harada and Takata, she has assumed that child benefit is a subsidy to husband's income and carried out her simulation analysis. Since a 10,000 yen child benefit is equivalent to $2.3 \%$ of husband's income, and one percent increase in husband's income decreases the "gap ratio" by $0.02 \%$, she has concluded that 10,000 yen child benefit will increase the number of children by $0.1 \%$. On the other hand, however, an increase in husband's income will increase the child care-cost, or quality of a child, thereby reducing the demand for more children. As a result, the net increase in the number of children born will be merely around $0.03 \%$, a very small magnitude for the cost. Unfortunately, for independent variables of both "gap" and care-cost functions, she has chosen household income, actual child care costs, and such other control variables as couple's ages, years of schooling, age of the oldest child, twin, and grandparents etc.. In fact, the only identifying variable of the child care-cost function is the sex ratio of children, which probably has made her TSLS estimation an exercise under weak instruments. In fact, she had to carry out the policy analysis by her OLS estimation results, rather than TSLS results.

\section{Nursery School Policies and Child-care leaves}

As we have seen earlier, securing child-care leave for working women have been one of the first significant measures of Japanese government to fight the fertility decline. As to child-care leave, there is a general consensus that it provides a powerful incentive for women to return to the same employer in a year. 
Many still question its effect on fertility, although there is some statistical evidence that women working for firms with child-care leave benefits tend to have more children. This positive correlation may simply reflect the sample selection, rather than causality, as women who wanted to have more children tried to get jobs in these firms with better maternity benefits. (Date and Shimizutani (2004))

The most important measure of the government to fight the fertility decline has been to provide better nursery school services. Again, most agree that accommodating more infants to public nursery schools provides good incentive for women to return to work, but not necessarily an incentive to have more children (Date and Shimizutani (2004), Nagase (2007)). On this policy, we will introduce three papers written by Yukiko Shigeno and her associates who had looked into women's decisions to have a child and work using the available micro-data in Japan. These are prime examples of how much the poor quality of available micro data has been limiting the economic researches in Japan.

Shigeno and Okusa (1998), using Japanese Panel Survey of Consumers, have estimated a bivariate probit model of getting married and returning to work for the same employer. They have found that child-care leave does not affect the marriage decision, but it seems to encourage women to return to the same employer. Unfortunately, the study is far too ambitious for its modest panel data; their sample of single female in the first survey was only 446 , of which only $10 \%$ got married in the second year, and $78 \%$ returned to the same employer. Thus we should not draw it is not wise to make definitive negative statement should be made regarding the effect of child-care leave on getting married.

Shigeno and Okusa(1999) attempted to estimate a very elaborate econometric model to analyze how the improved public nursery school services influence women's decision to have a child, and then another decision to return to work. Using a pooled datasets of National Basic Survey of '86, '89, '92, and '95, they have estimated a probit equation for having a child, and then estimated a second probit equation conditional on having a child. They found a strong evidence that nursery school services influences women's return to work, but did not find any conclusive evidence on their effects on fertility. The second part of their conclusion has to be discounted, however, due to less than an ideal nature of their data for their fertility equation. Since Basic Survey is not a panel data, they needed to construct a retrospective panel from a cross-section data. They selected married women without children and married women with only one child less than one year old for their first probit equation. Thanks to the large sample size of Basic Survey, they still managed to secure more than 10,000 samples. Unfortunately, (1) they had to do with prefecture averages for municipal nursery school services, because community information was not made available, and (2) even by limiting to households with children less than one year old, the available household information can be almost 2 years too old for fertility decision-making.

Shigeno and Matsuura (2003) has analyzed the effects of the child-care leave and the subjective quality of public nursery school on the child-bearing behavior of married, working women. For this purpose, they first estimated a bivariate probit model of marriage and work decisions and obtained the two inverse Mill's ratios and correlation coefficient for selecting married working women, using 1993 to 1997 data of Japanese Panel Survey of Consumers (JPSC). They then estimated a probit function for having the first child using the subsample of married working women, with dummy variables for child-care leave $(+$ expected), quality public nursery school (+ expected), and self-employed women (+ expected), as well as age, own expected earnings (- expected), husband's expected earnings (+ expected), and the two lambdas as their independent variables. Their results show that all the variables have expected signs, with child-care 
leave and own expected earnings having statistically significant coefficients. With only 227 samples in the second stage, however, clearly we cannot rule out the possibility that most of the variables with the right sign would gain statistical significance in a decent-sized panel data.

\section{An Index of Regional Fertility: a weighted fertility rate index}

\section{Factors of Regional Variation in Fertility}

Since it is very difficult to obtain large micro-data sets on family structure, the most frequently used fertility rates in empirical researches are prefecture total fertility rates, computed by the National Institute of Population and Social Security Research. There are 47 prefectures and, historically, there has always been a substantial variation across prefectures in terms of TFR (Fig. 1). Most conspicuous has been the relatively low fertility rates in prefectures that contain such large cities as Sapporo, Sendai, Tokyo, Kyoto, Yokohama, Osaka, Kobe and Fukuoka compared with their surrounding prefectures. There are many factors in living in large cities that can reasonably lead to low fertilities.

For one thing, due to expensive housing costs, most married couples live within a very limited space, and, adding a new member to a family can immediately create tensions to the existing family members. Secondly, most live far from workplace, and long commuting hours make it very difficult for husbands to share caring for the children. Thirdly, many young parents have come from smaller cities to attend colleges, and won't be able to get help from the grandparents of children. Fourthly, with respect to public nursery schools, in the capital areas usually it has been extremely difficult to place their infants in those facilities, and, a couple has to choose between a job and taking care of her baby. For a wife to continue to work, she usually has to place her baby in an expensive, but often low-quality, private nursery facility. Fifthly, the systematic disparities between big cities and smaller ones do not end there, but continues up to public high schools. Most big cities have admission capacity far less than half of the junior high school graduates, that helped develop strong but far more expensive private school system, while smaller cities accommodate most of the academically qualified students in their public schools.

Why then have most of the statistical works using prefecture level data failed to produce conclusive evidences on this reasonable conjecture? The problem, we believe, has to do with the heterogeneities within one prefecture concerning the factors that affect fertility. For instance, typically, in most prefectures other than metropolitan areas, there is a considerable concentration of population in its capital city, but the rest of the prefecture can be sparsely populated. As a result, in its capital city, jobs are easier to find, nursery schools are much harder to find, the housing costs are several times more expensive, and other costs of living can be far more expensive, than the rest of the prefecture. It has been very difficult to produce high quality statistical work based on prefecture data, which are averages of two very different areas.

For this reason, in our empirical work, we want to utilize the larger variation in the explanatory variables available in municipal data. Prior to 2002 , there used to be 3300 municipalities (i.e. cities, towns and villages), and after the Great Merger of 2002, there are still more than 2000 of them. Many of the data necessary for our statistical work are available only for census years, but it is a small price to pay if we get 40 times or more observations.

What should we choose for the fertility data? In general, demographers regard TFR as an ideal index for 
the measurement of fertility, and apparently annual municipal TFR data are available. On a national level, or even on a prefectural level, we agree that TFR should be the strongest candidate for our left hand side variable. For small towns or cities, however, it may be a very different story. In a small town, for instance, a few births this year may drastically increase the town's TFR, but almost surely depress it next year. Almost by definition, TFR for a small population will be very volatile over time, and what we have as municipal TFR will not come from vital statistics without some strong assumptions. If so, shouldn't we worry if the statistical process involved in computing community TFR interfere the regression analysis?

For this reason, we have opted to construct a normalized Weighted Fertility Rate index for our dependent variable. Its numerator is the total number of children born in a given year in a community, but our denominator is the expected number of children to be born there if all the women in the community had followed the reproductive pattern of an average Japanese woman of the same age in a base year. We have chosen year 1995 as our base year, because it is the mid-point of our five census years. If in a given year, before or after 1995, the women in the community followed an identical reproductive behavior to their national counterparts of 1995, the ratio will be one. If all of them are twice more reproductive, the ratio will be two, and so on. If we are sure that relative incidence of child-bearing remain the same across ages, our normalized WFR index multiplied by national TRF figure of 1995 gives a good estimate of its true TFR value.

On the other hand, the relative incidences of births across different ages can be substantially different in a town from the 1995 national pattern, even when it has an identical TFR value to the national TFR. In this case, our normalized WFR index will give a value that is either greater or less than one. This is an undesirable property for a proxy of TFR. We do not know, a priori, how well our weighted fertility rate approximates the TFR, nor can we test it directly on municipalities since TFR data are not available for them.

So we have tested it on the prefecture data for which TFR data are available. In order to avoid complications due to difference in the base of computation in Japanese vital statistics, we have chosen the following short-cut; for the number of new born children, rather than using the Vital Statistics figure, we have taken the weighted average of population who are 0 year old and population who are one year old. Since the Census is conducted on October 1 , we have given a weight of 0.75 to the 0 year old population and 0.25 to the 1 year old population.

In Figure 2, we have shown the five scatter diagrams between the log of prefecture TFR's and the log of weighted fertility rates for the last five census years, 1985, 1990, 1995, 2000 and 2005. Note that except for 2005, the two are aligned almost perfectly on a straight line. In fact, for our four census years, a simple regression of log of TFR on log of 1995 WFR index gives a coefficient of 1.019 ( $\mathrm{sd}=0.009$ ) and a $\mathrm{R}$ squared value of 0.9845 , while for the year 2005, the coefficient of log of WFR drops to 0.9579 ( $\mathrm{sd}=0.040$ ) and to an $R$ squared value of 0.9245. Even though there is some evidence of structural change, for the rest of this paper, we will still treat the 1995 WFR index as a good proxy of TFR for all these years including 2005. For all of the five census years, the coefficient of log of 1995 WFR index is 1.034 ( $\mathrm{sd}=0.0148)$ and a R2 of 0.9534 . In what follows, we assume that the same holds for municipalities as well. 


\section{Model and Data Sources}

\subsection{Model}

The model we are going to estimate is a standard linear model given by

$$
y_{i t}=\alpha_{i}+\sum_{j}^{J} \beta_{j} x_{i j t}
$$

where $y_{i t}$ is the log of an index of fertility rate of community $i$ in year $t$, and $x_{i j t}$ is the jth factor of community $\mathrm{i}$ in year $\mathrm{t}$.

The explanatory variables have been chosen so as to include all the important factors associated with the costs of raising children are captured. Overall there are four such groups of factors; namely, (1) labor market factors, (2) housing market factors, (3) public support for children, and (4) family structures (other than labor market factors).

\section{Labor Market Factors}

Among labor market factors, the most important is the opportunity cost of mother's time spent in raising children. Many variables can work as a good or reasonable proxy for this cost, including mother's education, female wage rates, and female labor force participation rates. The second factor is the income of families who want to start having children. In a traditional society where a husband is expected to be the main bread-winner, male wage rates or some household income index will serve as income variables. We will use the tax-base of the local income tax as a proxy of the family income. Also there are important public policies relieving women of the social insurance premiums during, and some period after, their child-care leaves.

\section{Housing Market Factors ,}

Children consume considerable space and the relative price of space can be an important limiting factor in the demand for children. Land price should serve as a good proxy for this cost. Since land price data is available only for the last three censuses, we will use population density as a proxy for the housing cost.

\section{Public Support for Raising Children}

While Japanese government spends relatively smaller amount for children compared with what they spend for the elderly, several programs have grown in its importance in relieving the child-raising costs or adding to the family income for families raising children.

- Availability of nursery school or day-care center services

- Partial or total payments of out-of-pocket costs of children's health care

- Cash grants for families with small children

\section{Family Structures}

If a couple has a support from their parents in looking after their children when they need it, raising children can become less costly and much safer. In this sense, multi-generation family structure is expected to be more child-friendly. Also, if women can look after their children while earning some income, it should lower the opportunity cost of women's time spent for raising children. It is often pointed out that self-employed families have this advantage, because they work and they live in the same places, and they 
have flexible working environments to meet the demands of child-cares.

\subsection{Data Sources}

Dependent Variable

The number of children born within one year of the census of year $t$ is denoted by Rbaby ${ }_{i t}$ and it is precisely zero (0) year old population of the community; namely,

$$
\text { Rbaby }_{i t}=P_{i t}(0) \text {, }
$$

where $P_{i t}(k)$ is the population of k year old in community i in year t. Assuming every women follow the average reproductive behavior of Japanese female observed in year 1995, the expected number of children born in the community E95baby $_{i t}$ is given by

$$
\text { E95 Baby }{ }_{i t}=\sum_{k=15}^{49} r 95_{k} F_{i t}(k) \text {, }
$$

where $r 95_{k}$ is the birth rate of Japanese women at age $\mathrm{k}$ in year 1995 and $F_{i t}(k)$ is the community's female population of age $\mathrm{k}$ in year $\mathrm{t}$.

Our dependent variable is $W_{F R} 95_{i t}$ which is the ratio of EBaby ${ }_{i t}$ to E95Baby ${ }_{i t}$, or

$$
\text { WFR95 }_{i t}=\text { RBaby }_{i t} / \text { E95Baby }_{i t} \text {. }
$$

In other words, WFR95 ${ }_{i t}$ shows how many times more babies the female population of the community is producing than are expected from the national average of the year 1995.

\section{Independent Variables}

> Child Welfare Expenditures is a normalized measure of municipal government's total expenditures for child. Specifically, we take a ratio of the total municipal expenditures for child welfare to its E95Baby, the hypothetical number of expected babies. We note that we used this normalization to avoid the endogeneity problem that would have occurred if we had used the actual number of babies born in the community. The municipal government's total expenditure for child welfare typically includes such items as (a) the costs of running public nursery schools, (b) the costs of child benefits, and (c) the costs of running various programs to prevent child-abuses. The recent increase in this variable is mainly due to (b). The source of this data is the Survey of the Financial Statements of Local Government compiled by Ministry of Home Affaires every year.

$>$ Per Capita Income is a proxy for personal income. More precisely, we have taken the reported tax base figure of the personal local income tax of the community contained in the Survey of Financial Statements of Local Governments, and divide it by the number of residents who are at age 15 or older. Then we normalize this income by dividing 1995 based GDP deflator

> Weighted Male Unemployment Rate measures the probability of being unemployed for a male in the child-raising ages in a given community. More specifically, starting from age 20 24, and up to age 45 49, first we have computed the ratio of actual number of unemployed males of each age-class to the expected number of unemployed males from the national average in the community. We then multiplied the ratio of each age-class by a weight equal to its national female fertility 
rate of 1995 (0.02234 for 20-24, 0.07791 for $25-29,0.10288$ for $30-34,0.05533$ for $35-39,0.01458$ for 40-44, and 0.00299 for 45-49) and computed the sum of the product. Although our index is not population-weighted, since the sum of the fertility weights is equal to 0.27603 , roughly speaking, we would expect a figure around 0.27 for the year 1995 .

$>$ Weighted Female LF Participation Rates measure the probability of a female in a child-bearing age to be in Labor Force in a given community, compared with the national average in 1995. More specifically, again, starting at age $20 \sim 24$, and up to age $40 \sim 44$, we have computed the LFP rates of each age-class in the community. We then give each age-class a weight equal to the female fertility rate of 1995, and compute the weighted female LFP rate.

$>$ Nuclear Family Ratio is the ratio of the number of two-generation households (including single parents households) to the sum of all types of households in each municipality.

$>$ Self-Employed Worker Ratio is simply the ratio of the self-employed workers in the population. It has been computed as follows; first, we obtained the number of workers in the self-employed business by adding the number of self-owned business owners and their workers in owner's family, and then we divided this number by the population of each municipality.

For this paper, we had to drop variables concerning available of nursery school services, as too many municipalities have missing values in the nursery school capacities. Including the variable would have resulted in a substantial loss of observations. Also, some would question the use of female labor force participation rate as an independent variable for its possible endogeneity problem. We would have been much more comfortable with some wage variables, but no wage information is available on a municipal level.

\subsection{Data structure and excluded data}

There were 2,238 municipalities in Japan on October 1, 2005, when 2005 Census was taken. We have constructed a panel data of these 2,238 municipalities for the five census years since 1985. A large number of mergers among municipalities took place during the first five years of the 21 st century. If town A, town $\mathrm{B}$ and town $\mathrm{C}$ merged to form a new city D in year 2002, for example, in our data, we have data only for City D from 1985 to 2005. Consequently, in principle, our panel data is a balanced panel data, but, in our census, some data are missing systematically in some regions for various reasons. In particular, for an unknown reason, all municipalities in Chiba prefecture for year 1985 are not accounted for, and, all municipal data in Hyogo prefecture for year 1995 are not accounted for due to "Kobe Earthquake". Likewise we had to exclude all Miyake village data. We also excluded 6 municipalities in Akita prefecture in 2005 because of missing value.

\subsection{Descriptive Statistics}

Our Table 2 shows the descriptive statistics of these variables in the pooled cross-section data, including the variables (from Rbaby to Base LF Female) used to compute the variables of our regression. Here WFRindex stands for WFR95 $_{\text {it }}$.

Our next table, Table 3, shows the means of these variables at each 5 year interval during these twenty 
years. It is clear that, among the variables of the table, "WFRindex", "In(WFR index)" and "Self-Employed Ratio" have downward trends, while the rest have more or less upward trends. Especially, we note that the increase in "Male Unemployment Ratio" is steep during the 2000-2005 period: it was 0.324 in year 2000, which went up to 0.502 in year 2005.

\section{Estimation Results}

The results of our regression estimation are given in Table 4. The first two columns give the results of OLS, pooled cross-section regressions, without community dummies. The first column of the table gives the coefficients of equation with year dummies. The second gives the coefficients of the equation without year dummies. Finally, the third column gives the more interesting results as it gives the estimated coefficients of fixed effect model.

\section{Baseline OLS Estimation Result}

In the first column of Table 4, it looks as though we have gotten almost all we have hoped for. Child welfare expenditures increased the fertility, but the actual magnitude of its effect is very small. An additional one million yen per child spent for child welfare increases the fertility by 1.6 percent, which seems to be a very small effect. This is typical of econometric estimation results as we have discussed earlier, but this does not mean that its effect is negligible. For one thing, the standard deviation of this variable is about 2 million yen, so this expenditure is making a difference of at least several percentage points in fertility between urban communities that have below average expenditures and rural communities that have above average expenditures.

As expected, a higher share of Nuclear Family as well as a higher population density reduces the fertility. Although unit increase in the Nuclear Family share reduces the fertility 7 percent, the standard deviation of this variable is very small (0.088), and we should conclude that its effect is fairly limited. Likewise, unit increase in population density (measured by thousand individuals per one square kilometer) reduces the fertility by 1.5 percent. This variable primarily stands for higher unit land price, and the variation in this variable is very large. In 2005, for instance, national average was 0.89 , but the values of this variable for twenty three center districts of Tokyo averaged 13.7, for Osaka 11.8, for Kawasaki City 9.3, for Yokohama City 8.2, for Nagoya City 6.8 etc.. Thus higher land price presumably reduces the fertility in major Japanese cities significantly, from 10 percent for Nagoya, and to almost 20 percent for Tokyo.

Two labor market variables have coefficients with the expected sign and statistical significance. An Increase in job insecurity of young male worker's reduces the fertility substantially; in fact, in a community where the unemployment variable takes the value of 1 , or four times of the 1995 national average (0.259), the fertility is reduced by 23.8 percent. The standard deviation of men's job insecurity variable is 0.19 , and between a 25 percentile community $(0.164)$ and a 75 percentile community (0.386), we expect a 5 percentage point reduction in fertility.

Another is the higher "risk" of women who are in the labor force; it reduces the fertility as expected. In fact, young women's Weighted Labor Force Participation variable has the largest coefficient (-0.557). The standard deviation of the variable, however, is very small (0.04), and between a 25 percentile community $(0.277)$ and a 75 percentile community (0.333), we can expect only a 3 percentage point reduction in fertility. 
The only oddity in the OLS result is the negative coefficient of household income (-0.1767), with very high statistical significance. In fact, in our own experience, this phenomenon is quite common in OLS regressions of fertility using prefecture data, and it is usually a strong sign of important missing variables in the OLS specification. Many economic variables move in the same way as the income variables, and the negative income coefficient suggests that it is serving as a proxy for these missing variables that exert negative influences on fertility. If the estimated equation is not correctly specified, furthermore, we can no longer rule out the possibility that these missing variables may be biasing the estimated coefficients of variables other than income. A prime candidate for such a variable is education levels of each cohort, which are only available once in 10 years in our census, and we had to do without them.

Lastly, coefficients of year dummies indicate that our baseline fertility has been declining continuously during the 1990 to 2005 period, on average, at the rate of almost one percentage point per year.

The second column shows that, if we remove the year dummies, two changes will take place: one, self-employed ratio emerges as a significant positive factor of fertility, and, two, Labor Market Participation of females in child-bearing ages exerts even greater negative influence on fertility. This model too seems to be suffering from the negative coefficient problem of family income proxy variable.

\section{Fixed Effect Model Estimation Results}

In view of the possible important missing variables, therefore, in the third column of Table 4, we have estimated the fixed effect model. This estimation should give us a more accurate picture of what has happened during this period.

Regarding the household income, although it still has a negative coefficient, it is now very small and no longer statistically significant. Presumably, this shows that we have successfully absorbed the important missing variables that are correlated with income, including education, in the fixed effects of prefectures. This comes at a price, however, as we had to drop population density variable that has too little variation within most municipalities.

One of the most significant change is the coefficient of the Nuclear Family Ratio (-0.3105) which is more than four times as large as the base line estimation (-0.0718). Our conclusion, however, will not change too much as far as the importance of this variable is concerned in fertility decline. From Table 3, the means of this variable have changed very little over the last two decades, from 0.550 in 1985 to 0.561 in 2005, and it is still unlikely that this factor accounts much of the decline in fertility during this period.

Another large change is in the coefficient of Weighted Female LFP ratio (-1.502) which is almost three times as large as the baseline estimate (-0.5573). Nevertheless, the conclusion remains unchanged; from Table 3, the means of this variable have increased from 0.288 in 1985 to 0.322 in 2005 , and this variable accounts for a decline in fertility of around six percentage points over the two decades.

In contrast, the coefficient of unemployment variable of young male workers $(-0.1536)$ has been reduced to two-thirds of the baseline estimate (-0.2384). Again from Table 3, in view of the considerable increase in the weighted risk of young male workers, from 0.218 in 1985 to 0.502 in 2005, it still accounts for a decline in fertility of four percentage points over the two decades.

Concerning the effect of public policies, it is still true that the child welfare expenditures variable is highly significant, but the size of the effect (0.0038) is now only one-third of the baseline estimate. In spite 
of the large increases in this variable, from 1.676 million yen in 1985 to 4.306 million yen in 2005, it still accounts for one percent increase in the number of children born during this period.

\section{Discussion and Concluding Remarks}

What can we learn from our estimation? Let us first summarize our estimation results; using the coefficients obtained in Table 4, we have decomposed the changes in our WFR index in Table 5. Please note, however, that our decompositions are based on sample means, and as such, they are not population weighted.

(1) We can see in the first row (Total Changes) of the table that the fertility declined by $10.5 \%$ during the first period, and the decline slowed down to $4.4 \%$ for the second period, but it increased again to $8.4 \%$ for the third, and $7.8 \%$ for the last period. Thus apparently the decline has not eased at all.

(2) If we look at the second row, however, the unexplained factors (namely, coefficients of year dummies) contributed $8.8 \%$ in the first period, but only $3.0 \%$ in the second period. But in the third period it went up to $5.9 \%$, and came down to $3.6 \%$ in the last period.

(3) The third row reveals the sum of the explained parts for these four periods. Note that the explained sum only accounted for $1.7 \%$ in the first period, $1.5 \%$ in the second, but it increased in the third to $2.5 \%$ and in the fourth periods to $4.3 \%$.

(a) The fourth row gives the effect of the pro-child public policy. For all of the periods, it accounted for small but steady influences on fertility around $0.2 \%$ to $0.3 \%$.

(b) The eighth row gives the effect of the young men's labor market. It had a positive influence only in the first period, and in the second and third periods, it had a negative influence of $1 \%$. In the last period, however, its influence climbed to minus $2.7 \%$.

(c) The last row gives the effect of the young women's labor market. For three of the four periods, it had a negative influence

Based on these results, we would like to offer the following four observations.

First, we want to point out that most of the "unexplained" changes in Table 5 probably reflect the reduced preferences for children in young women. These factors are not controlled at all in our regression. It then appears that the reduced preference for children was the dominant factor during $1985 \sim 1989$ period, and again 1995 1999 period. But after year 2000, this factor seems to be losing some of its steam. As a result, for the first time during the last twenty years, since year 2000, more than half of the decline can be attributed to the changes in economic factors, particularly labor market factors.

Secondly, Table 5 shows that, during the last period, the most important factor in the decline was the labor market uncertainty of young men, although increased labor market participation of young women continue to contribute significantly to the decline. As we have seen, public pro-fertility policies during the last two decades have focused mostly on women and children, leaving out young men who were having extreme difficulty in the labor market. In fact, unemployment is only a part of their problems, as Genda (2003) has maintained, the preferential treatments of the elderly workers in public policies could have deprived them of opportunities for life-cycle skill-formation. Our result shows that economic deprivation of 
younger men accounts for an important part of the continued stagnation of Japanese fertility.

Thirdly, the same results suggest that child-care benefits can be a very important pro-fertility policy. As we have seen in the review of the existing literature, some argue that the effects of benefits are likely to be very small on the basis of estimated coefficients of some other variables, but it is noteworthy that none of them are based on direct statistical evidence. The point we want to make is simply that if economic uncertainty imposed on young couples is such an important obstacle to having the children they want, then providing more generous child benefits should be an efficient way to reduce the uncertainty. As we have shown in Table 1, the benefits have been too small, and the rules have been too restrictive and complex. With strong commitment in the benefits, our results suggest that the benefits can make a real difference in the young couple's reproductive behavior.

Our last point is on the effectiveness of the public nursery school as a pro-fertility policy. As we have seen, most existing studies agree that improving public nursery school services contributes to women's employment after maternity or child-care leaves. As to the effect on fertility, some show a small positive effect, while most show no effect. Because our variable includes both the costs of child benefits and public nursery school programs, we cannot single out the effect of improved public nursery school services. Our result is, however, consistent with the view that they had a small positive effect on fertility. As Nagase (2007) noted recently, improvement in public nursery schools since the Angel Plan has been very uneven; during the 1988-2004 period, 12 prefectures had capacity increases between $40 \%$ and $70 \%$, but Tokyo had only $12 \%$ and Kanagawa $23 \%$. In large cities, the shortage has been filled by private nursery schools, but their care is far inferior and their costs are at least twice or more expensive than public ones. As Nagase argues, a new approach similar to the long-term care insurance will improve the efficiency and equity of the nursery care a great deal.

Lastly, a good news for Japanese fertility is the massive retirement of baby boomers in the next few years. To replace them, firms have started hiring the young male workers. This could turn the economic fortunes of younger male workers around completely, and remove the negative pressure on the Japanese fertility. In fact, we may start to see gradual recovery in fertility for the next decade or so.

\section{Reference}

(In English)

Genda, Y. (2003) "Who Really Lost Jobs in Japan?: Youth Employment in an Aging Japanese Society", Ogura, S., Tachibanaki, T., and Wise, D. ed., Labor Markets and Fringe Benefit Policies in Japan and the United States, pp.103-133, The University of Chicago Press, Chicago.

\section{(In Japanese)}

Abe K., and Harada Y. (2008): "Kosodate Shiensaku no Kyusshouritu ni Ataeru Eikyo- ShiChoSon Deta no Bunseki" (The impact of the pronatalist programs on total fertility rates in Japan: an empirical analysis using the city and district level data), Kaikei Kensa In Kenkyu, vol. 38, 103-118.

Date Y., and Shimizutani S. (2005): "Why Has Japan's Fertility Rate Declined? An Empirical Literature Survey with an Emphasis on Policy Implications”, Economic Analysis, vol. 176, 93-135

Harada Y., and Takata S. (1993) "Jinko no Riron to Syorai Suikei", (Population Theory and Population 
Projection), in Takayama N., and Harada Y. ed. Koureika no Naka no Kinyu to Chochiku. p1-16.

Higuchi, Y. etl. (2007) "Tiikiyouin ga Tuma no Syugyokeizoku ni Oyobosu Eikyo ni Tuite -Kakei Keizai Kennkyujyo 'Syohiseikatu ni Kansuru panel Tyosa' ni yoru Bunseki”, 07-J-012, RIETI Discussion Paper Series.

Kitamura, Y. and Miyazaki, T (2009): "Kekkon Keikenritsu to Syussyoryoku no Chiikikan Kakusa:Jissyoteki Survey”, Nihon Keizai Kenkyu, No.60, pp.79-102.

Morita, Y. (2004): "Kosodate Hiyo to Syussei Koudou" (Child-Care Costs and Child Bearing Behaviors), Nihon Keizai Kenkyu, No.48, pp1-24.

Nagase, N.(2007): "Shoshika ni Kakawaru Seisaku wa Doredake Jikkou Saretanoka? Hoiku to Jidou Ikusei ni kansuru Seisaku no Kadai “ ( How Has Japan Answered the Policy Challenges Concerning Nursery Care and Child Development?), Financial Review, No.87, pp.3-22.

Ogura, S. and Dekle, R. (1992): “1970nen Ikou no Syusseiritu no Teika to SonoGennin”, JCER Economic Journal, vol. 22, p16-76.

Sasai, T. (2005): "The fertility trends and their determinants of differentials for Japan's municipalities", J. of Population Problem, vol. 61, no3, p39-49.

Shigeno, Y. and Matsuura K. (2003):”Syussann Ikuji to Syugyo no Ryoritsu wo Mezasite-Kekkon Syugo Sentaku to Kikon Syugyo Josei ni Taisuru Ikuji Kyugyo no Koka wo Chushin ni" (Seeking Compatibility between Child Birth/Care and Employment: Analysis of Marriage Employment Selection and the Effect of Child Care Leave on Married Working Women ) in Kikan Shakai Hosho Kenkyu, vol.39, No.1, pp43-54.

Shigeno, Y. and Ohkusa Y. (1998), "Ikuji Kyugo Seido no Josei no Kekkon to Syugyo Keizoku he no Eikyo" (The Effect of Child Care Leave Program on the Marriage of Women and Their Working Without Quit), in Nihon Rhodo Kenkyu Zassi, vol.40(9), pp39-49.

Shigeno, Y. and Ohkusa Y. (1999), "Hoiku Seisaku ga Syussan no IshiKettei to Syugo ni Ataeru Eikyo" (The Effect of Nursery School Policies on Women's Child Birth Decisions and Employment) in Kikan Shakai Hosho Kenkyu, vol.35 No.2, pp192-207

Takayama, T. etl. (2000): "The Cost of Marriage and Child Care and Its Effect on Fertility: A Note on the Economic Factors of Below-Replacement Fertility in Japan”, J. of Population Problems, vol. 56 no4, p1-18. 
Figure 1. Prefectural TFR in Census Years (1985-2005)

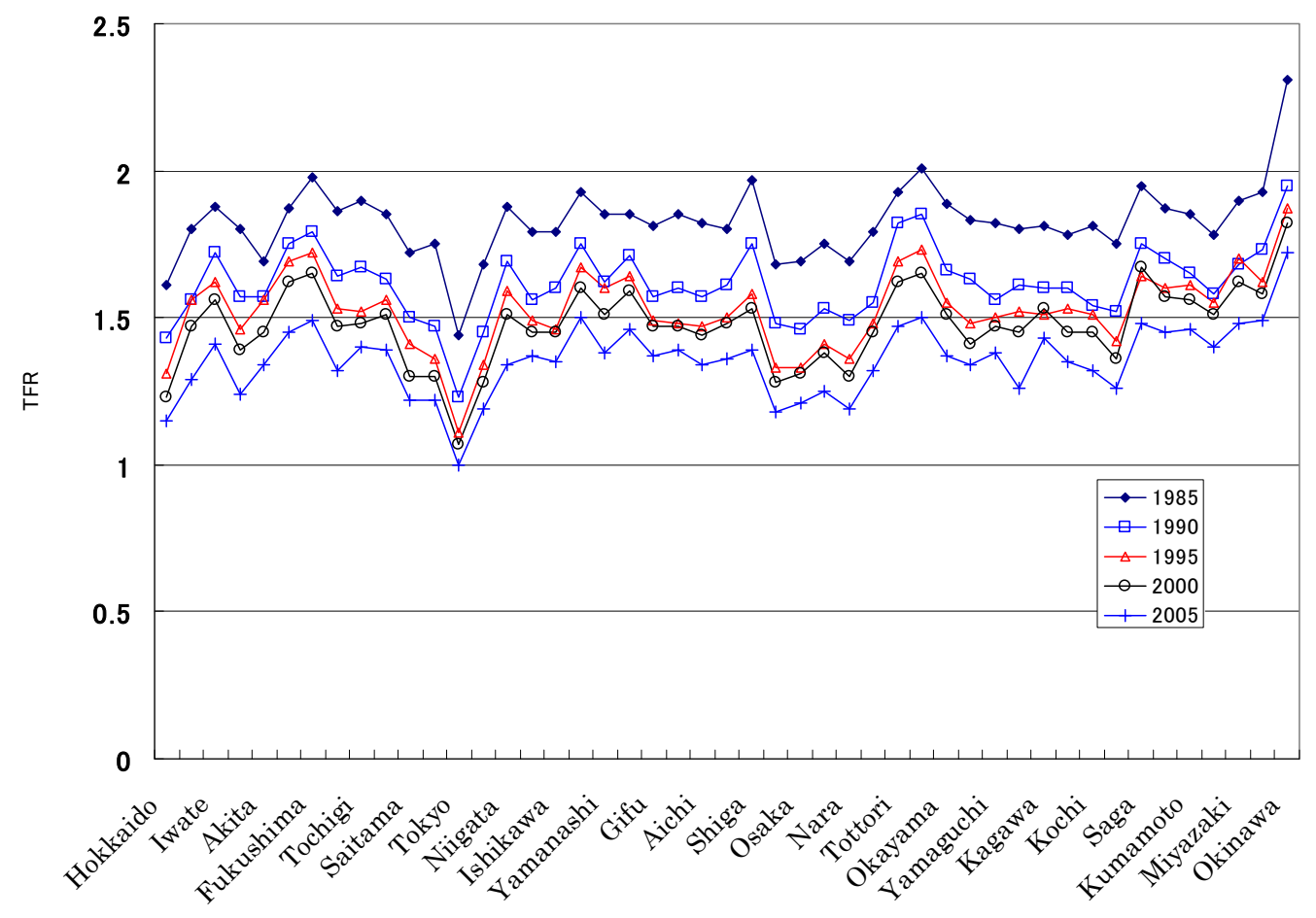


Figure 2. Scatter Diagrams of log of TFR (lntfr) and log of WFRidx95 (lnidx95) for Prefectures for Census Years (1985-2005)

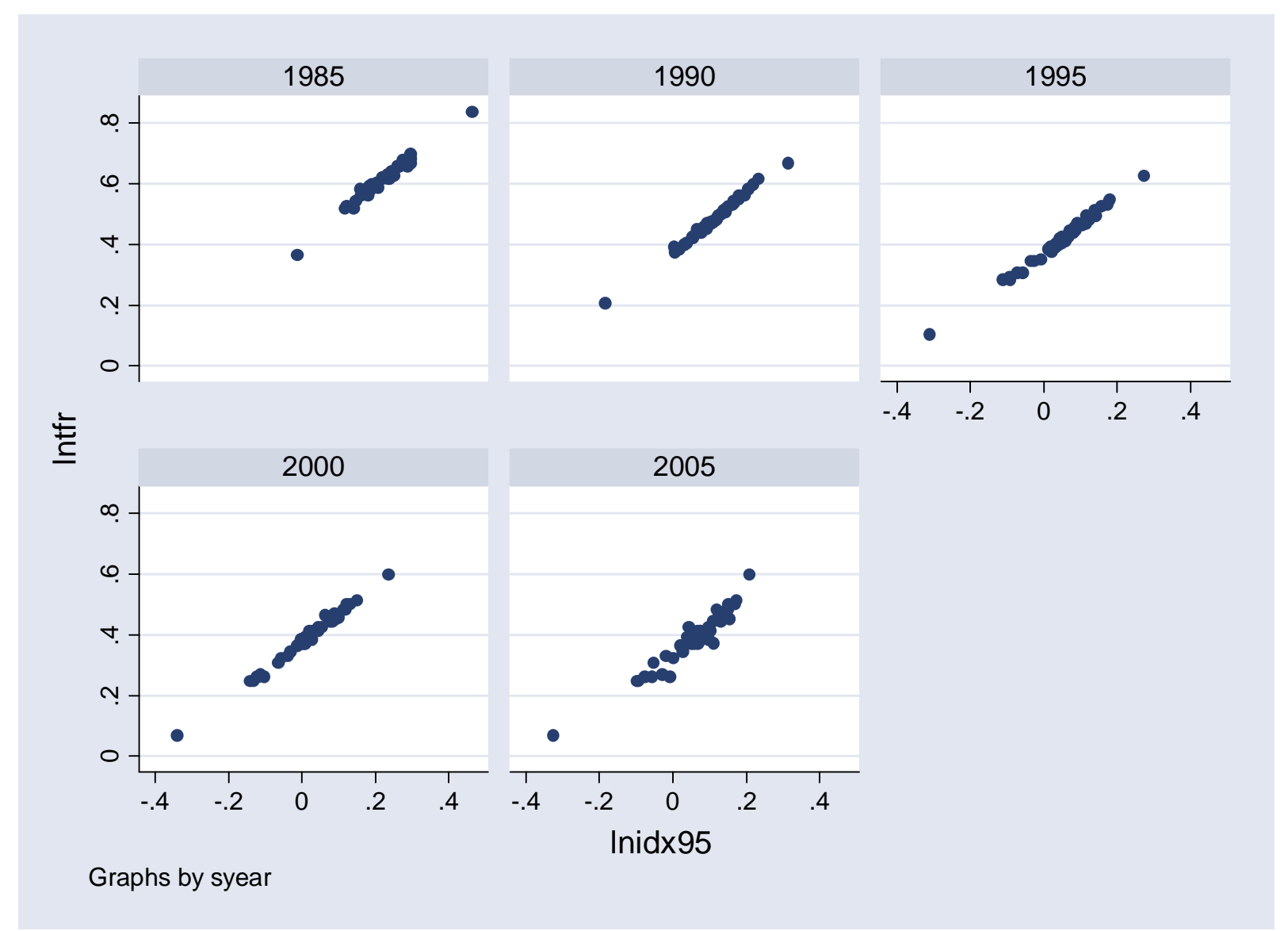


Table 1 Changes in Japanese Child-Care Benefits

1) Benefits are monthly figure in yen, subject to household income limits

2) "<5" means "less than 5 years old"

3) Admission age to primary school is assumed to be 6 years old

\begin{tabular}{|c|c|c|c|c|c|c|c|c|}
\hline & \multicolumn{2}{|c|}{ 1st Child } & \multicolumn{2}{|c|}{ 2nd Child } & \multicolumn{2}{|c|}{ 3rd Child or Later } & \multirow{2}{*}{$\begin{array}{l}\text { Number of } \\
\text { Children } \\
\text { Receiving } \\
\text { Benefits (1000) }\end{array}$} & \multirow{2}{*}{$\begin{array}{l}\text { Cost of Benefits } \\
\text { (billion yen) }\end{array}$} \\
\hline & Age & Benefits & Age & Benefits & Age & Benefits & & \\
\hline 1972 & & & & & $<5$ & 3,000 & 1,299 & 42 \\
\hline 1973 & & & & & $<10$ & 3,000 & 2,032 & 74 \\
\hline 1974 & & & & & $<12$ & 4,000 & 2,341 & 106 \\
\hline 1975 & & & & & $<12$ & 5,000 & 2,404 & 144 \\
\hline 1986 & & & $<2$ & 2,500 & $<15$ & 5,000 & 2,961 & 160 \\
\hline 1987 & & & $<4$ & 5,000 & $<9$ & 5,000 & 3,226 & 155 \\
\hline 1988 & & & $<6$ & 5,000 & $<6$ & 5,000 & 3,248 & 145 \\
\hline 1991 & $<1$ & 5,000 & $<5$ & 5,000 & $<5$ & 5,000 & 2,573 & 138 \\
\hline 1992 & $<2$ & 5,000 & $<4$ & 5,000 & $<4$ & 10,000 & 2,415 & 215 \\
\hline 1993 & $<3$ & 5,000 & $<3$ & 5,000 & $<3$ & 10,000 & 2,215 & 194 \\
\hline 1999 & & & & & & & 2,164 & 159 \\
\hline 2000 & $<6$ & 5,000 & $<6$ & 5,000 & $<6$ & 10,000 & 4,831 & 293 \\
\hline 2004 & $<9$ & 5,000 & $<10$ & 5,000 & $<11$ & 10,000 & 7,473 & 593 \\
\hline 2006 & $<12$ & 5,000 & $<12$ & 5,000 & $<12$ & 10,000 & 9,273 & 807 \\
\hline 2007 & $<3$ & 10,000 & $<3$ & 10,000 & $<3$ & 10,000 & 9,295 & 975 \\
\hline & $<12$ & 5,000 & $<12$ & 5,000 & $<12$ & 10,000 & & \\
\hline
\end{tabular}

Sources: White Papers of Ministry of Health and Welfare etc. 
Table 2: Descriptive Statistics

\begin{tabular}{|c|c|c|c|c|c|c|c|c|}
\hline Variable & & Mean & Std. Dev. & Min. & p25 & Med. & p75 & Max. \\
\hline WFR index & & 1.12 & 0.244 & 0 & 0.962 & 1.107 & 1.257 & 3.668 \\
\hline $\ln (W F R$ index $)$ & & 0.09 & 0.22 & -2.026 & -0.039 & 0.102 & 0.229 & 1.3 \\
\hline Per Capita Child Welfar Expenditure (million Yen) & & 2.971 & 2.026 & 0.108 & 1.667 & 2.506 & 3.745 & 39.347 \\
\hline Per Capita Income (million Yen) & & 1.621 & 0.487 & 0.411 & 1.273 & 1.636 & 1.949 & 7.747 \\
\hline Nuclear Family Ratio & & 0.555 & 0.088 & 0.232 & 0.495 & 0.559 & 0.619 & 0.79 \\
\hline Self-Employed Ratio & & 0.278 & 0.114 & 0.067 & 0.189 & 0.262 & 0.351 & 0.846 \\
\hline Population Density (thousand individuals/km2) & & 0.855 & 2.037 & 0.002 & 0.073 & 0.22 & 0.619 & 21.334 \\
\hline Male Unemployment Ratio & & 0.299 & 0.191 & 0 & 0.164 & 0.256 & 0.386 & 1.919 \\
\hline Female LFP Ratio & & 0.305 & 0.042 & 0.101 & 0.277 & 0.305 & 0.333 & 0.444 \\
\hline Rbaby (Numerator of WFR index) & & 538 & 1522 & 0 & 61 & 148 & 440 & 35678 \\
\hline E95baby (Denominator of WFR index) & & 537 & 1649 & 1 & 54 & 133 & 394 & 39291 \\
\hline Child Welfare Expenditure (million Yen) & & 1201 & 3716 & 1 & 146 & 336 & 931 & 112516 \\
\hline \multirow[t]{6}{*}{ Unemployed Male } & $20<=$ age $<25$ & 106 & 348 & 0 & 9 & 27 & 77 & 10436 \\
\hline & $25<=$ age $<30$ & 91 & 331 & 0 & 7 & 19 & 61 & 11403 \\
\hline & $30<=$ age $<35$ & 72 & 271 & 0 & 5 & 16 & 49 & 11680 \\
\hline & $35<=$ age $<40$ & 61 & 224 & 0 & 5 & 15 & 43 & 9620 \\
\hline & $40<=$ age $<45$ & 55 & 194 & 0 & 5 & 14 & 40 & 8118 \\
\hline & $45<=$ age $<49$ & 55 & 197 & 0 & 5 & 14 & 41 & 7246 \\
\hline \multirow[t]{6}{*}{ Base Unemployed Male } & $20<=$ age $<25$ & 109 & 363 & 0 & 9 & 24 & 69 & 8980 \\
\hline & $25<=$ age $<30$ & 88 & 282 & 0 & 9 & 21 & 62 & 7276 \\
\hline & $30<=$ age $<35$ & 64 & 198 & 0 & 7 & 16 & 48 & 5272 \\
\hline & $35<=$ age $<40$ & 54 & 161 & 0 & 6 & 15 & 43 & 4322 \\
\hline & $40<=$ age $<45$ & 55 & 156 & 0 & 7 & 15 & 44 & 4037 \\
\hline & $45<=$ age $<49$ & 53 & 148 & 0 & 7 & 16 & 43 & 3891 \\
\hline \multirow[t]{5}{*}{$\begin{array}{l}\text { Working Female } \\
\text {. }\end{array}$} & $20<=$ age $<25$ & 1258 & 3924 & 0 & 119 & 308 & 897 & 92767 \\
\hline & $25<=$ age $<30$ & 1148 & 3555 & 0 & 116 & 288 & 847 & 94624 \\
\hline & $30<=$ age $<35$ & 998 & 2815 & 1 & 124 & 293 & 820 & 82164 \\
\hline & $35<=$ age $<40$ & 1132 & 2939 & 2 & 157 & 365 & 989 & 73369 \\
\hline & $40<=$ age $<45$ & 1301 & 3363 & 2 & 181 & 420 & 1135 & 76125 \\
\hline \multirow[t]{5}{*}{ Base LF Female } & $20<=$ age $<25$ & 1279 & 4098 & 1 & 112 & 293 & 873 & 96210 \\
\hline & $25<=$ age $<30$ & 1161 & 3635 & 2 & 113 & 279 & 837 & 89558 \\
\hline & $30<=$ age $<35$ & 970 & 2937 & 1 & 102 & 248 & 733 & 78149 \\
\hline & $35<=$ age $<40$ & 1121 & 3267 & 2 & 128 & 306 & 880 & 83048 \\
\hline & $40<=$ age $<45$ & 1296 & 3686 & 1 & 155 & 364 & 1029 & 92111 \\
\hline
\end{tabular}


Table 3: Discriptive Statistics:

obs.=11045 (obs. of $\ln ($ WFR index $)=11042)$

\begin{tabular}{|c|c|c|c|c|c|c|c|}
\hline \multicolumn{2}{|c|}{ means by year } & 1985 & 1990 & 1995 & 2000 & 2005 & Total \\
\hline \multicolumn{2}{|l|}{ WFR index } & 1.298 & 1.174 & 1.129 & 1.04 & 0.964 & 1.12 \\
\hline \multicolumn{2}{|l|}{$\ln ($ WFR index) } & 0.25 & 0.145 & 0.101 & 0.018 & -0.061 & 0.09 \\
\hline \multicolumn{2}{|c|}{ Per Capita Child Welfar Expenditure } & 1.676 & 2.243 & 3.029 & 3.562 & 4.306 & 2.971 \\
\hline \multicolumn{2}{|c|}{ Per Capita Income (million Yen) } & 1.093 & 1.443 & 1.846 & 1.907 & 1.803 & 1.621 \\
\hline \multicolumn{2}{|l|}{ Nuclear Family Ratio } & 0.55 & 0.552 & 0.552 & 0.558 & 0.561 & 0.555 \\
\hline \multicolumn{2}{|l|}{ Self-Employed Ratio } & 0.347 & 0.303 & 0.268 & 0.242 & 0.234 & 0.278 \\
\hline \multicolumn{2}{|c|}{ Population Density (thousand individuals $/ \mathrm{km}^{\wedge}{ }^{2}$ ) } & 0.791 & 0.851 & 0.858 & 0.879 & 0.893 & 0.855 \\
\hline \multicolumn{2}{|l|}{ Male Unemployment Ratio } & 0.218 & 0.187 & 0.259 & 0.324 & 0.502 & 0.299 \\
\hline \multicolumn{2}{|l|}{ Female LFP Ratio } & 0.288 & 0.3 & 0.302 & 0.311 & 0.322 & 0.305 \\
\hline \multicolumn{2}{|c|}{ Rbaby (Numerator of WFR index) } & 631 & 543 & 522 & 524 & 473 & 538 \\
\hline \multicolumn{2}{|c|}{ E95baby (Denominator of WFR index etc.) } & 527 & 511 & 530 & 574 & 543 & 537 \\
\hline \multicolumn{2}{|c|}{ Child Welfare Expenditure (million Yen) } & 718 & 895 & 1130 & 1436 & 1808 & 1201 \\
\hline \multirow[t]{6}{*}{ Unemployed Male } & $20<=$ age $<25$ & 70 & 76 & 124 & 123 & 136 & 106 \\
\hline & $25<=$ age $<30$ & 55 & 50 & 90 & 120 & 139 & 91 \\
\hline & $30<=$ age $<35$ & 57 & 37 & 59 & 82 & 126 & 72 \\
\hline & $35<=$ age $<40$ & 59 & 41 & 47 & 60 & 100 & 61 \\
\hline & $40<=$ age $<45$ & 42 & 44 & 55 & 52 & 80 & 55 \\
\hline & $45<=$ age $<49$ & 41 & 33 & 62 & 64 & 74 & 55 \\
\hline \multirow[t]{6}{*}{ Base Unemployed Male } & $20<=$ age $<25$ & 103 & 112 & 125 & 109 & 95 & 109 \\
\hline & $25<=$ age $<30$ & 80 & 84 & 90 & 101 & 85 & 88 \\
\hline & $30<=$ age $<35$ & 66 & 58 & 60 & 66 & 72 & 64 \\
\hline & $35<=$ age $<40$ & 65 & 55 & 48 & 50 & 54 & 54 \\
\hline & $40<=$ age $<45$ & 55 & 66 & 55 & 48 & 50 & 55 \\
\hline & $45<=$ age $<49$ & 48 & 54 & 63 & 54 & 46 & 53 \\
\hline \multirow[t]{5}{*}{ Working Female } & $20<=$ age $<25$ & 1241 & 1399 & 1469 & 1199 & 987 & 1258 \\
\hline & $25<=$ age $<30$ & 888 & 1046 & 1184 & 1405 & 1208 & 1148 \\
\hline & $30<=$ age $<35$ & 953 & 851 & 897 & 1043 & 1241 & 998 \\
\hline & $35<=$ age $<40$ & 1333 & 1167 & 983 & 1037 & 1142 & 1132 \\
\hline & $40<=$ age $<45$ & 1300 & 1559 & 1298 & 1150 & 1198 & 1301 \\
\hline \multirow[t]{5}{*}{ Base LF Female } & $20<=$ age $<25$ & 1221 & 1328 & 1466 & 1274 & 1111 & 1279 \\
\hline & $25<=$ age $<30$ & 1060 & 1107 & 1180 & 1331 & 1122 & 1161 \\
\hline & $30<=$ age $<35$ & 1004 & 876 & 891 & 983 & 1094 & 970 \\
\hline & $35<=$ age $<40$ & 1338 & 1155 & 976 & 1031 & 1110 & 1121 \\
\hline & $40<=$ age $<45$ & 1318 & 1556 & 1292 & 1139 & 1178 & 1296 \\
\hline
\end{tabular}


Table 4 Regression Results

$(* 10 \%, * * 5 \%, * * * 1 \%)$

\begin{tabular}{|c|c|c|c|c|c|c|c|c|}
\hline \multicolumn{2}{|c|}{ Dependen Variables : $\ln (\mathrm{WFI})$} & \multicolumn{2}{|c|}{ With Year Dummies } & \multicolumn{2}{|c|}{ W/O Year Dummies } & \multicolumn{3}{|c|}{ Fixed Effect Model } \\
\hline \multicolumn{2}{|c|}{ Explanatory Variables } & Coef. & Std. Err. & Coef. & Std. Err. & Coef. & Std. Err. & \\
\hline \multicolumn{2}{|c|}{ Per Capita Child Welfar Expenditure } & 0.0159 & $0.0010^{* * *}$ & 0.0118 & $0.0010 \quad * * *$ & 0.0038 & 0.0013 & *** \\
\hline \multicolumn{2}{|c|}{ Per Capita Income (million Yen) } & -0.1767 & $0.0062 * * *$ & -0.2042 & $0.0048 * * *$ & -0.002 & 0.0119 & \\
\hline \multicolumn{2}{|c|}{ Nuclear Family Ratio } & -0.0718 & $0.0249 * * *$ & -0.1029 & $0.0253 * * *$ & -0.3105 & 0.0641 & $* * *$ \\
\hline \multicolumn{2}{|c|}{ Self-Employed Ratio } & 0.0297 & 0.0213 & 0.0906 & $0.0215 * * *$ & 0.0802 & 0.0597 & \\
\hline \multicolumn{2}{|c|}{ Population Density (thousand individuals/km2) } & -0.0147 & $0.0009 * * *$ & -0.0131 & $0.0009 * * *$ & & & $* * *$ \\
\hline \multicolumn{2}{|c|}{ Male Unemployment Ratio } & -0.2384 & $0.0122 * * *$ & -0.3466 & $0.0097 * * *$ & -0.1536 & 0.0166 & $* * *$ \\
\hline \multicolumn{2}{|c|}{ Female LFP Ratio } & -0.5573 & $0.0555 * *$ & -0.8832 & $0.0535 * * *$ & -1.502 & 0.0859 & $* * *$ \\
\hline \multirow[t]{4}{*}{ Year dummy } & 1985 & 0.016 & $0.0071 * * *$ & & & 0.1136 & 0.0112 & $* * *$ \\
\hline & 1990 & -0.0343 & $0.0059 * * *$ & & & 0.0305 & 0.0069 & $* * *$ \\
\hline & 1995 & -0.0598 & $0.0053 * * *$ & & & -0.0577 & 0.0047 & *** \\
\hline & 2005 & -0.1188 & $0.0062 * * *$ & & & -0.093 & 0.0068 & $* * *$ \\
\hline \multirow[t]{3}{*}{ Constant Tern } & & 0.6541 & 0.0316 *** & 0.8012 & 0.0284 & 0.7372 & 0.0544 & $* * *$ \\
\hline & & \multicolumn{2}{|c|}{$\begin{array}{c}\mathbf{F}(11,11030)=676.76 \\
\text { Prob > F }=0.0000 \\
\text { R2 }=0.4030 \\
\text { AdjR2 }=0.4024 \\
\text { RMSE }=0.17001\end{array}$} & \multicolumn{2}{|c|}{$\begin{array}{c}\mathbf{F}(7,11035)=965.36 \\
\text { Prob }>\mathbf{F}=0.0000 \\
\text { R2 }=0.3798 \\
\text { AdjR2 }=0.3794 \\
\text { RMSE }=0.17324 \\
\end{array}$} & \multicolumn{3}{|c|}{$\begin{array}{c}\text { Number of groups }=2237 \\
\text { Obs per group: } \min =2 \\
\text { avg }=4.9 \\
\max =5 \\
\text { R2: } \quad \\
\text { within }=0.4516 \\
\text { between }=0.0007 \\
\text { overall }=0.2034 \\
\mathbf{F}(10,8795)=724.24 \\
\text { Prob }>\mathbf{F}=0.0000 \\
\text { corr }\left(\mathrm{u} \_\mathrm{i}, \mathrm{Xb}\right)=-0.1009\end{array}$} \\
\hline & & & & & & $\begin{array}{r}\text { sigma } \\
\text { sigma } \\
\text { rho } \\
\text { F test: } \\
\text { F(2236, } \\
\text { Prob > }\end{array}$ & $\begin{array}{l}\mathrm{u}=0.1575 \\
\mathrm{e}=0.1330 \\
0.5839 \\
\text { ll } \mathrm{u}_{-} \mathrm{i}=0: \\
795)=4.31 \\
\mathrm{~F}=0.0000\end{array}$ & \\
\hline
\end{tabular}


Table 5 Factor Decomposition Base on Fixed Effect Model

\begin{tabular}{|c|c|c|c|c|}
\hline & 1985-1989 & 1990-1994 & 1995-1999 & $2000-2004$ \\
\hline Total Changes & -0.1048 & -0.0444 & -0.0837 & -0.0782 \\
\hline Unexplained & -0.0879 & -0.0298 & -0.0586 & -0.0357 \\
\hline Explained sum & -0.0168 & -0.0146 & -0.0250 & -0.0425 \\
\hline Per Capita Child Welfar Expenditure & 0.0021 & 0.0030 & 0.0020 & 0.0028 \\
\hline Per Capita Income (million Yen) & -0.0007 & -0.0008 & -0.0001 & 0.0002 \\
\hline Nuclear Family Ratio & -0.0008 & 0.0002 & -0.0021 & -0.0009 \\
\hline Self-Employed Ratio & -0.0036 & -0.0028 & -0.0021 & -0.0006 \\
\hline Male Unemployment Ratio & 0.0047 & -0.0111 & -0.0100 & -0.0273 \\
\hline Female LFP Ratio & -0.0186 & -0.0031 & -0.0127 & -0.0167 \\
\hline
\end{tabular}

